\title{
Cervical Length Estimation and Cervicovaginal Fluid for Placental $\alpha$-Microglobulin 1 Testing to Screen Women Had Threatened Preterm Labor for Time till Spontaneous Labor
}

\author{
Mohamed Kandil*, Abdelhaseib Salah Saad, Alaa Masood \\ Departments of Obstetrics \& Gynecology, Faculty of Medicine, Menoufia University, Shibin El Kom, Egypt \\ Email: ${ }^{\star}$ mohamed.kandil.pf@gmail.com
}

How to cite this paper: Kandil, M., Saad, A.S. and Masood, A. (2020) Cervical Length Estimation and Cervicovaginal Fluid for Placental $\alpha$-Microglobulin 1 Testing to Screen Women Had Threatened Preterm Labor for Time till Spontaneous Labor. Advances in Reproductive Sciences, 8, 57-70.

https://doi.org/10.4236/arsci.2020.81006

Received: December 21, 2019

Accepted: January 19, 2020

Published: January 22, 2020

Copyright $\odot 2020$ by author(s) and Scientific Research Publishing Inc. This work is licensed under the Creative Commons Attribution International License (CC BY 4.0).

http://creativecommons.org/licenses/by/4.0/

\section{Open Access}

\begin{abstract}
Objectives: Evaluation of diagnostic performance of rapid testing of cervico-vaginal fluid (CVF) for fetal fibronectin (FFN) and placental $\alpha$-microglobulin 1 (PAMG-1) as screening of women presented by threatened preterm labor (TPTL) with intact membranes for duration till getting spontaneous labor (SL). Patients \& Methods: 37 women presenting with TPTL underwent CVF samplings before digital examination and then underwent transvaginal ultrasonography for estimation of cervical length (CL). All women received fluid and anxiolytic therapy and if uterine contractions persisted, all had received tocolytic therapy with oral nifedipine or intravenous magnesium sulphate according to requirements. Incidence of SL within $<48 \mathrm{hr}, 2-7$ and $7-14$ days was recorded and related to CL and result of FFN and PAMG-1 tests. Results: Incidence of SL was 13.5\%, 35.2\% and 51.3\% within $48-\mathrm{hr}, 2-7$ and 7 - 14 days, respectively. Duration till labor after sampling was positively correlated with $\mathrm{CL}$, while was negatively correlated with positive FFN and PAMG-1 tests. Positive FFN test had high specificity, while positive PAMG-1 test had high sensitivity for labor within 7 days. Regression analysis defined short CL and positive PAMG-1 test as significant predictors for short duration till SL. ROC curve analysis defined short cervix and positive PAMG-1 test as significant predictors for labor within $48-\mathrm{hr}$ and within 2 - 7 days respectively and combined negative PAMG-1 test and CL of $20-25 \mathrm{~mm}$ were significant predictors for labor within 7 - 14 days. Conclusion: PAMG-1 test had high specificity, if positive, for predicting SL and high NPP, if negative, for excluding labor within 7 days, so it can be used as rapid adjuvant to clinical evaluation to help management decision-making. Moreover, PAMG-1 test is recommended screening test for being easy-to-use bedside test, provides
\end{abstract}


rapid results, can be used after vaginal exam and coitus and does not require a speculum examination or specialized equipment to analyze results.

\section{Keywords}

Threatened Preterm Labor, Cervico-Vaginal Fluid, Fetal Fibronectin, Placental $\alpha$-Microglobulin 1, Screening, Spontaneous Labor

\section{Introduction}

Threatened preterm labor (TPTL) can be defined as the occurrence of regular uterine contractions before completion of 37 gestational weeks (GW) at rate of one contraction per ten minutes and persists for more than 30 minutes without cervical dilatation [1]. TPTL is associated with neonatal morbidity and mortality as well as maternal morbidity induced by antepartum bed rest and unnecessary treatment [2].

Risk stratification in women with preterm contractions would allow targeting of interventions to women who will indeed deliver preterm and avoiding unnecessary treatments, associated with potential complications, in symptomatic women who are unlikely to deliver preterm [3]. Cervical length (CL) measurement in women with TPTL showed modest accuracy for predicting PTB [4] and combined with fetal fibronectin (FFN) testing may allow risk stratification for spontaneous delivery in women still pregnant 7 days after TPTL [5].

Fetal fibronectin is an extracellular matrix glycoprotein which is produced by amniocytes and cytotrophoblasts [6]. FFN acts normally as glue between maternal decidua and amniotic membranes [7]. FFN can be detected in cervico-vaginal fluid (CVF) in all pregnancies before $22 \mathrm{GW}$, but between 24 and $34 \mathrm{GW}$ indicates a risk of impending PTL [8] when its concentration in CVF is $\geq 50 \mathrm{ng} / \mathrm{ml}$, but it showed no adequate sensitivity or specificity to predict a delay of labor at term [9]. For prediction of PTL within 7 days, quantitative FFN measurement was not superior to qualitative test with CL, but added more costs [10]. Accuracy of combined serial CL measurements and FFN for predicting PTB in nulliparous patients was reported to be low [11]. Blood-stained swabs of CVF for FFN testing were still effective for predicting PTL, but had higher false positive rates [12].

Placental $\alpha$-microglobulin-1 (PAMG-1) is a human $34 \mathrm{kd}$ fetal glycoprotein that was first isolated in 1975 from amniotic fluid [13]. PAMG-1 is an endometrial protein produced by uterine glands since $1^{\text {st }}$ trimester of pregnancy [14]. PAMG-1 is present in the amniotic fluid (AF) and CVF of pregnant women. However, its concentration in AF of pregnant women (2000 - 25,000 $\mathrm{ng} / \mathrm{ml}$ ) is several thousand higher than that found in CVF when the fetal membranes are intact $(0.05-0.2 \mathrm{ng} / \mathrm{ml})$ [15]. PAMG-1 is not present in urine and at low levels in maternal blood, thus reducing the risk of inaccurate results in the presence of other fluids [16]. 


\subsection{Objectives}

Evaluation of diagnostic performance of cervico-vaginal fluid (CVF) for fetal fibronectin (FFN) and placental $\alpha$-microglobulin 1 (PAMG-1) as rapid screening of women presented by threatened preterm labor (TPTL) with intact membranes for duration till getting spontaneous labor (SL).

\subsection{Design}

Prospective clinical intervention.

\subsection{Setting}

Obstetrics \& Gynecology Department, Faculty of Medicine, Menoufia University.

\section{Materials \& Methods}

The current study was conducted since Jan 2017 after approval of the study protocol by the Local Ethical Committee. All women presenting with TPTL which is defined as development of painful regular uterine contractions persisting for $>30$ minutes at a rate of one contraction/10 minutes at gestational age (GA) of 24 $35 \mathrm{GW}$ without cervical dilatation [17] were eligible for evaluations.

Exclusion criteria included cervical dilatation $\geq 3 \mathrm{~cm}$, vaginal bleeding, vaginal discharge, uterine over distention secondary to multiple gestations or polyhydramnios or multiple gestations, systemic infection, fever $>38^{\circ} \mathrm{C}$, fetal distress, intrauterine growth restriction, blood pressure $\geq 140 / 90$ and $\leq 100 / 60 \mathrm{mmHg}$, any obstetric contraindications to tocolytic agents, and history of any thromboembolic disorders. All women were clinically evaluated without digital examination or insertion of speculum until cervical secretion swabs were obtained. Then, vaginal examination was performed and speculum was inserted to assure the cervical status if closed or obtained and if opened membranes were bulging at the level of external os or not. Transvaginal ultrasonography was performed, with empty bladder and minimal pressure, the shortest length between the internal and external os was measures with clearest image after 3 measurements, before and after Valsalva's maneuver [18].

\subsection{Vaginal Sample Obtaining and Testing}

According to manufacturer instructions, vaginal samples were obtained for qualitative evaluation of the presence of fFN and PAMG-1 in cervical secretions. Sampling was postponed in women had digital examination or intercourse within 24-hr before attending to the hospital. Also, sampling was prohibited in women had vaginal bleeding or infection.

1.Sample I: Before speculum examination, blind vaginal sample (sample-I) was obtained using a sterile flocked swab that was inserted $5-7 \mathrm{~cm}$ into the vagina for $30 \mathrm{~s}$, removed and then was placed in a vial containing buffer solution and actively rotated in the buffer for $30 \mathrm{~s}$. Then, the swab was removed and a test strip for PAMG-1 (The PartoSure Immunoassay Kit, Parsagen Diagnostics, Inc., 
Boston, USA) was incubated in the buffer solution for $5 \mathrm{~min}$ and then was removed to be read. Test is positive on appearance of two red lines at control and test sites, negative if only one red line appeared at control site and invalid is only one red line appeared at test site.

2.Sample II: Speculum was inserted and a sterile Dacron swab was rotated in the posterior fornix of the vagina for $10 \mathrm{~s}$. Then the swab was inserted into a tube containing buffer solution in which it was thoroughly mixed for $10-15 \mathrm{~s}$, was removed and a test strip for FFN (QuikCheck ${ }^{\mathrm{TM}} \mathrm{FFN}$, Hologic ${ }^{\odot}$ ) was incubated in the buffer for 10 min, removed and read. Positive FFN test (two lines) suggest cervical secretion FFN concentration is $>50 \mathrm{ng} / \mathrm{mL}$, or negative (single line).

\subsection{Management}

On admission, all women were asked to relax and stay in bed for 1-hr, and administered Lactated Ringer's solution $500 \mathrm{ml}$ and $50 \mathrm{mg}$ pethidine (Meperidine hydrochloride, Dolantin). If uterine contractions persisted, oral nifedipine (Adalat capsules, Bayer AG) $20 \mathrm{mg}$ as a loading dose, then every $30 \mathrm{~min}$ till uterine contractions stop; for a maximum total of 3 doses. After regular uterine contractions stopped, a maintenance dose using nifedipine $20 \mathrm{mg}$ was given orally every 8 hours for 48 -hr [19]. Then, uterine contractions were monitored by continuous electrical external fetal monitoring for $90 \mathrm{~min}$ after the loading dose and then every uterine contractions and fetal heart sounds were monitored every 6 for 24 hours [20]. During follow-up, maternal blood pressure was recorded every $15 \mathrm{~min}$ for 2-hr after the loading dose, and every 6-hr for 48-hr with monitoring for the side effects of nifedipine.

Management outcome was considered successful if no contractions recurred after inhibition for $12 \mathrm{~h}$ by nifedipine and patients were maintained on maintenance dose until 34 weeks of gestation. In case of continued or recurred uterine contractions after inhibition for $12-\mathrm{hr}$, Intravenous magnesium sulphate was administered as $4 \mathrm{~g}$ loading dose of $4 \mathrm{gm}$ followed by $2 \mathrm{gm} / \mathrm{hr}$ continuous infusion that was increased by $1 \mathrm{~g} / \mathrm{hr}$ hourly until successful tocolysis or failure of treatment [21].

\subsection{Study Outcomes}

Study outcomes included the incidence of spontaneous PTB within $<48 \mathrm{hr}, 2$ - 7 and 7 - 14 days and the relation of this incidence to cervical length and result of FFN and PAMG-1 tests. The diagnostic performance criteria (sensitivity, specificity, positive and negative predictive values and positive and negative likelihood ratios) of CL and FFN and PAMG-1 tests for prediction of such outcome were evaluated.

\subsection{Statistical Analysis}

Obtained data were presented as mean \pm SD, numbers and percentages. Possible 
relationships were investigated using Pearson linear regression analysis. The diagnostic performance criteria (sensitivity, specificity, positive and negative predictive values and positive and negative likelihood ratios) of CL and FFN and PAMG-1 tests were calculated versus the time of delivery as a true positive event. Regression analysis (Stepwise method) was used for stratification of studied parameters as specific predictors. Sensitivity \& specificity of studied parameters as predictors for time till SL were evaluated using the receiver operating characteristic (ROC) curve analysis judged by the area under the curve (AUC) that was compared versus null hypothesis that AUC $=0.5$. Statistical analysis was conducted using the IBM SPSS (Version 23, 2015; IBM, South Wacker Drive, Chicago, USA) for Windows statistical package. $\mathrm{p}$ value $<0.05$ was considered statistically significant.

\section{Results}

Through duration of study 45 women presented with manifestations of threatened PTB; 8 women were excluded for not fulfilling inclusion criteria and 37 women were enrolled in the study (Figure 1). The study included 37 women in age range of $18-37$ with a mean age of $28.5 \pm 6.4$ years and mean BMI of $29.6 \pm$ $5.5 \mathrm{~kg} / \mathrm{m}^{2}$ with 16 women were obese with $\mathrm{BMI}>30 \mathrm{~kg} / \mathrm{m}^{2}$. All women were multigravida, but 21 women were nullipara. Majority of women had TPTB
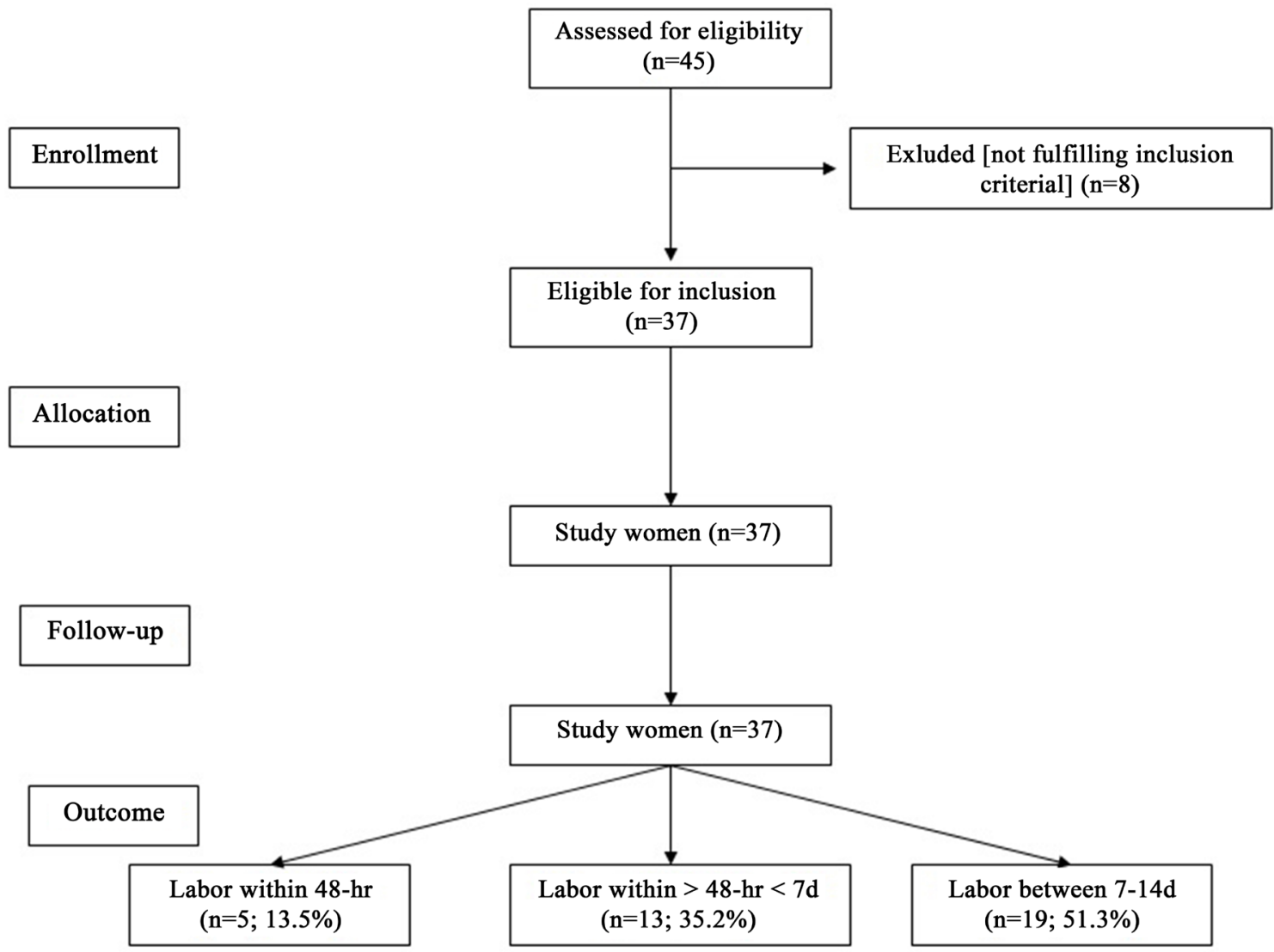
$(n=45)$

Figure 1. Consort flow sheet. 
manifestation in range of 24 - 28 GW. Details of enrollment data of studied women are shown in Table 1.

All enrolled women had short cervix as estimated at time of attendance with a mean CL of $18.9 \pm 4.6 \mathrm{~mm}$. Six women (16.2\%) had CL $<15 \mathrm{~mm}, 18$ women (48.6\%) had CL in range of $15-20 \mathrm{~mm}$ and 13 women (35.2\%) had CL in range of 21 - $24 \mathrm{~mm}$. Five women (13.5\%) had labor within 48-hr, 13 women (35.2\%) had labor within a range of 2 - 7 days and 19 women $(51.3 \%)$ had labor within a range of 7 - 14 days and <14 days. Regarding cervical secretion testing, 10 samples (27\%) were positive for FFN and 19 samples (51.3\%) were positive for PAMG-1, but only 7 samples (18.9\%) were positive for both tests.

Duration till labor after sampling showed positive significant correlation $(\mathrm{r}=$ $0.484, \mathrm{p}=0.002)$ with $\mathrm{CL}$, while showed negative significant correlation $(-0.404$, $\mathrm{p}=0.013)$ with positive PAMG-1 test. On the other hand, duration till labor after sampling showed negative non-significant $(\mathrm{r}=-0.247, \mathrm{p}=0.141)$ correlation with positive FFN test.

Evaluation of diagnostic performance criteria of studied tests detected low sensitivity of positive FFN test, while showed high specificity and +LR for prediction of labor during 48 hours or in range of 2 - 7 days after sampling. On

Table 1. Enrolment data of studied women presented by TPTL.

\begin{tabular}{|c|c|c|}
\hline \multicolumn{2}{|l|}{ Variables } & \multirow{2}{*}{$\begin{array}{c}\text { Findings } \\
1(2.7 \%)\end{array}$} \\
\hline Maternal age (years) & $\leq 20, \mathrm{n}(\%)$ & \\
\hline & $21-25, \mathrm{n}(\%)$ & $8(21.6 \%)$ \\
\hline & $26-30, \mathrm{n}(\%)$ & $16(43.3 \%)$ \\
\hline & $31-35, \mathrm{n}(\%)$ & $7(18.9 \%)$ \\
\hline & $>35, \mathrm{n}(\%)$ & $5(13.5 \%)$ \\
\hline & Mean $( \pm$ SD) & $28.5 \pm 6.4$ \\
\hline \multirow[t]{4}{*}{ Body mass index $\left(\mathrm{kg} / \mathrm{m}^{2}\right)$} & $<25, \mathrm{n}(\%)$ & $3(8.2 \%)$ \\
\hline & $25-30, \mathrm{n}(\%)$ & $18(48.6 \%)$ \\
\hline & $>30, \mathrm{n}(\%)$ & $16(43.2 \%)$ \\
\hline & Mean $( \pm$ SD) & $29.6 \pm 5.5$ \\
\hline \multirow[t]{3}{*}{ Gravidity } & G1, n (\%) & $15(40.5 \%)$ \\
\hline & G2, n (\%) & $12(32.5 \%)$ \\
\hline & G3, n (\%) & $10(27 \%)$ \\
\hline \multirow[t]{3}{*}{ Parity } & Nullipara, n (\%) & $21(56.8 \%)$ \\
\hline & Para-1, n (\%) & $11(29.7 \%)$ \\
\hline & Para-2, n (\%) & $5(13.5 \%)$ \\
\hline \multirow{4}{*}{$\begin{array}{c}\text { Gestational age at inclusion } \\
\text { (weeks) }\end{array}$} & $24, \mathrm{n}(\%)$ & $7(18.9 \%)$ \\
\hline & $>24-28, \mathrm{n}(\%)$ & $27(73 \%)$ \\
\hline & $>28, \mathrm{n}(\%)$ & $3(8.1 \%)$ \\
\hline & Mean $( \pm S D)$ & $26.1 \pm 4.6$ \\
\hline
\end{tabular}


contrary, positive PAMG-1 test showed high sensitivity for detection of women who will get labor within 48-hr or in range of 2 - 7 days after sampling. Moreover, negative PAMG-1 test can exclude the possibility of getting labor within 48-hr or within a range of $2-7$ days after sampling with high NPV $(89.47 \%$ \& $77.78 \%$, respectively). Positive sample for both FFN and PAMG-1 can define women at high risk of labor within 48-hr or within a range of $2-7$ days after sampling with high specificity ( $84.38 \%$ and $87.5 \%$, respectively) and + LR ( $2.56 \& 2.46$, respectively). Unfortunately, positive FFN and/or PAMG-1 tests had equivocal diagnostic performance criteria for prediction of labor after 7 days (Table 2).

Regression analysis of short CL, positive FFN test and positive PAMG-1 test for prediction of short duration between sampling time and getting labor defined short $\mathrm{CL}(\beta=0.441)$ and positive PAMG-1 test $(\beta=0.351)$ as significant ( $\mathrm{p}$ $=0.003 \& 0.016$, respectively) predictors.

ROC curve analysis of the predictability of short CL, and result of fFN and PAMG-1 tests for risk of labor within $<48$-hrs defined short cervix as significant sensitive predictor with AUC $=0.116(\mathrm{p}=0.006)$ (Figure 2), while negative PAMG-1 test was a significant specific predictor for postponing labor beyond >

Table 2. Diagnostic performance criteria of FFN and PAMG-1 testing of samples of cervical secretion of studied women presented by TPTL.

\begin{tabular}{|c|c|c|c|c|c|c|c|c|c|}
\hline & & & Sensitivity \% & Specificity \% & $+\mathrm{LR}$ & $-\mathrm{LR}$ & PPV\% & NPV\% & Accuracy \% \\
\hline \multirow[t]{6}{*}{$<48-\mathrm{hr}$} & Both FFN \& & Value & 40 & 84.38 & 2.56 & 0.71 & 28.57 & 90 & 78.38 \\
\hline & $\mathrm{P}$ & CI & $5.27-85.34$ & $67.21-94.72$ & $0.67-9.80$ & $0.34-1.48$ & $9.46-60.48$ & $81.25-94.92$ & $61.79-90.17$ \\
\hline & FFN test & Value & 40 & 75 & 1.60 & 0.80 & 20 & 88.89 & 70.27 \\
\hline & & $\mathrm{CI}$ & $5.27-85.34$ & $56.6-88.54$ & $0.47-5.47$ & $0.38-1.68$ & $6.81-46.1$ & $79.19-94.39$ & $53.02-84.13$ \\
\hline & PAMG-1 test & Value & 60 & 53.12 & 1.28 & 0.75 & 16.67 & 89.47 & 54.05 \\
\hline & & $\mathrm{CI}$ & $14.66-94.73$ & $34.74-70.91$ & $0.57-2.86$ & $0.25-2.31$ & $8.21-30.91$ & $73.46-96.31$ & $36.92-70.51$ \\
\hline \multirow{6}{*}{$\begin{array}{l}>48-\mathrm{hr}- \\
<7 \text { days }\end{array}$} & Both FFN \& & Value & 30.77 & 87.5 & 2.46 & 0.79 & 57.14 & 70 & 67.57 \\
\hline & PAMG-1 & $\mathrm{CI}$ & $9.09-61.43$ & $67.64-97.34$ & $0.65-9.36$ & $0.53-1.17$ & $25.95-83.53$ & $61.17-77.56$ & $50.21-81.99$ \\
\hline & FFN test & Value & 38.46 & 79.17 & 1.85 & 0.78 & 50 & 70.37 & 64.86 \\
\hline & & $\mathrm{CI}$ & $13.86-68.52$ & $57.85-92.87$ & $0.65-5.22$ & $0.48-1.25$ & $26.12-73.88$ & $59.60-79.27$ & $47.46-79.79$ \\
\hline & PAMG-1 test & Value & 69.23 & 58.33 & 1.66 & 0.53 & 47.37 & 77.78 & 62.16 \\
\hline & & CI & $38.57-90.91$ & $36.64-77.89$ & $0.92-3.02$ & $0.22-1.28$ & $33.15-62.03$ & $59.15-89.43$ & $44.76-77.54$ \\
\hline \multirow{6}{*}{$\begin{array}{c}>7- \\
<14 \text { days }\end{array}$} & Both FFN \& & Value & 5.26 & 66.67 & 0.16 & 1.42 & 14.29 & 40 & 35.14 \\
\hline & PAMG-1 & $\mathrm{CI}$ & $0.13-26.03$ & $40.99-86.66$ & $0.02-0.19$ & $1.01-2.00$ & $2.17-55.59$ & $32.11-48.45$ & $20.21-52.54$ \\
\hline & FFN test & Value & 16.67 & 63.16 & 0.45 & 1.32 & 30 & 44.44 & 40.54 \\
\hline & & CI & $3.58-41.42$ & $38.36-83.71$ & $0.14-1.49$ & $0.88-1.97$ & $11.54-48.46$ & $34.89-54.43$ & $24.75-57.9$ \\
\hline & PAMG-1 test & Value & 16.67 & 63.16 & 0.45 & 1.32 & 30 & 44.44 & 40.54 \\
\hline & & $\mathrm{CI}$ & $3.58-41.42$ & $38.36-83.71$ & $0.14-1.49$ & $0.88-1.97$ & $11.54-48.46$ & $34.89-54.43$ & $24.75-57.90$ \\
\hline
\end{tabular}

CI: Confidence interval; LR: Likelihood ratio; PPV: Positive predictive value; NPV: Negative predictive value; fFN: fetal fibronectin; PAMG-1: Placental $\alpha$-microglobulin-1; $\mathrm{p}<0.05$ indicates significant difference versus the null hypothesis that AUC $=0.5$. 
48-hr but to $<7$ days with AUC $=0.715(\mathrm{p}=0.033$ ) (Figure 3). On the other hand, negative PAMG-1 test as significant (AUC $=0.297, \mathrm{p}=0.035)$ sensitive and long cervix are significant ( $A U C=0.722, p=0.021$ ) specific predictors for good response to tocolytics and postponing of labor to occur within a range of 7 - 14 days (Table 3, Figure 4).

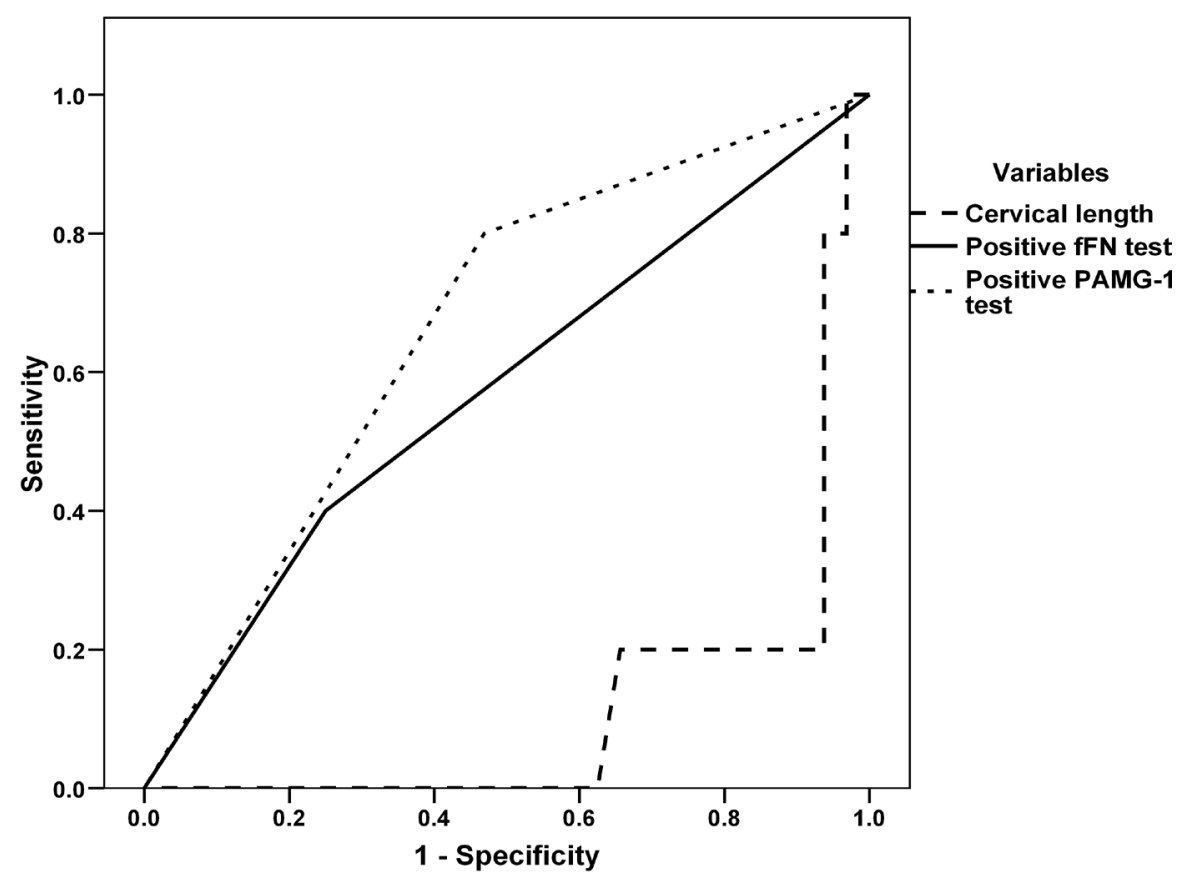

Figure 2. ROC curve analysis of studied variables for prediction of labor within 48 hours after sampling.

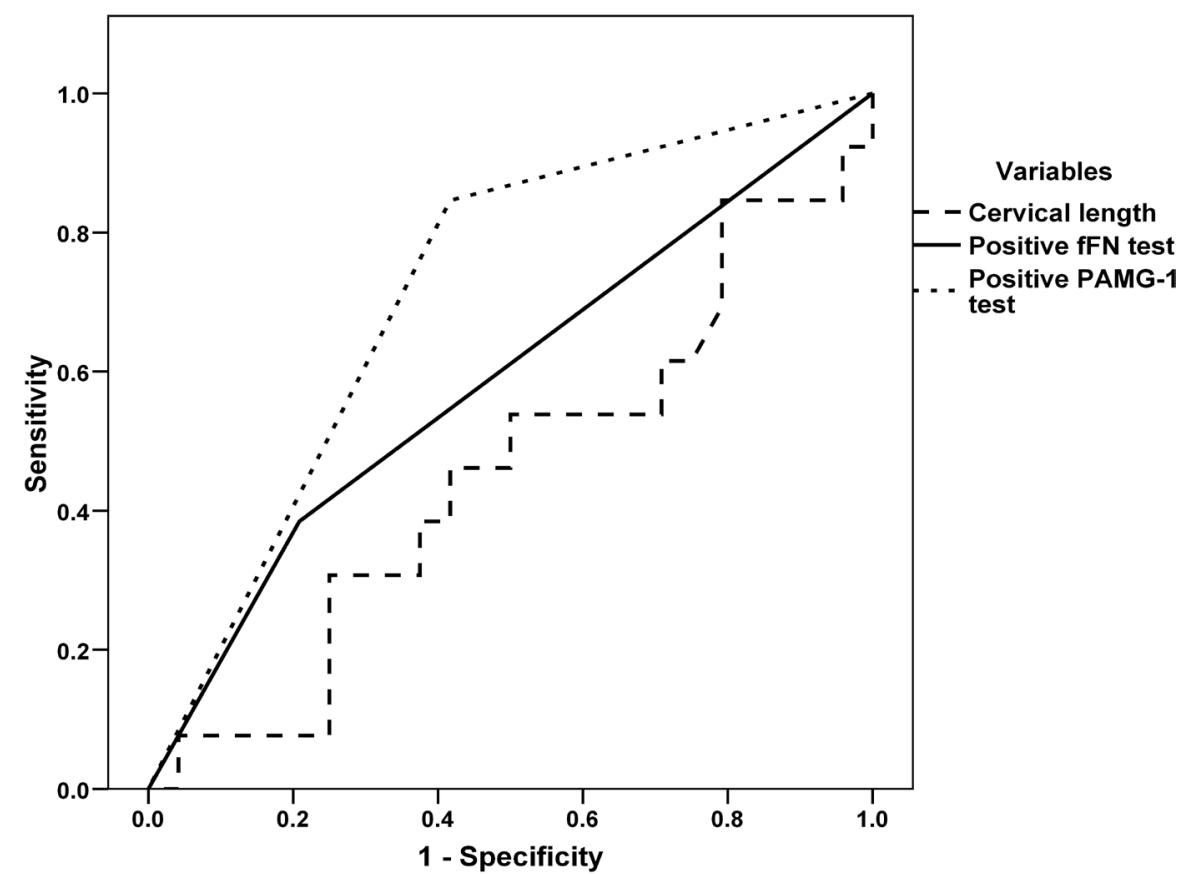

Figure 3. ROC curve analysis of studied variables for prediction of labor within $>48$-hrs $<7$ days after sampling. 


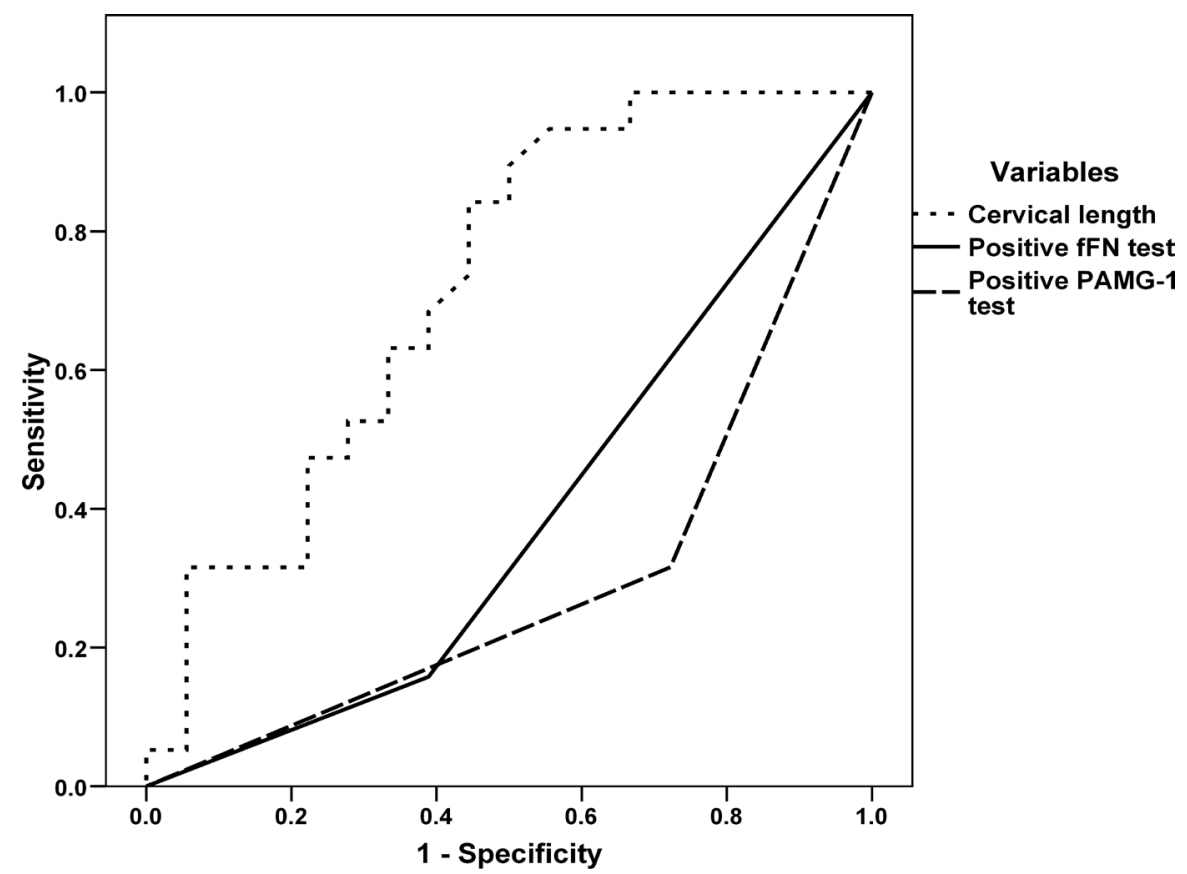

Figure 4. ROC curve analysis of studied variables for prediction of labor within $>7-<14$ days after sampling.

Table 3. ROC analysis of at enrolment cervical length and results of fFN and PAMG-1 tests of cervical secretion of studied women presented by TPTL.

\begin{tabular}{cccccc}
\hline Time of labor & Variables & AUC & SE & p & 95\% CI \\
\hline \multirow{2}{*}{ Within $<48 \mathrm{hr}$} & Cervical length & 0.116 & 0.069 & 0.006 & $0.20-0.251$ \\
& Positive FFN test & 0.575 & 0.144 & 0.594 & $0.292-0.858$ \\
& Positive PAMG-1 test & 0.666 & 0.123 & 0.239 & $0.425-0.907$ \\
$\begin{array}{c}\text { Within a range } \\
\text { of 2 - 7 days }\end{array}$ & Cervical length & 0.454 & 0.102 & 0.645 & $0.254-0.653$ \\
& Positive FFN test & 0.588 & 0.101 & 0.382 & $0.390-0.787$ \\
$\begin{array}{c}\text { Within a range } \\
\text { of 7 - 14 days }\end{array}$ & Negative PAMG-1 test & 0.715 & 0.087 & 0.033 & $0.544-0.886$ \\
& Negative PAMG-1 test & 0.297 & 0.088 & 0.035 & $0.125-0.469$ \\
\hline
\end{tabular}

AUC: Area under curve; SE: Standard error; CI: Confidence interval; FFN: fetal fibronectin; PAMG-1: Placental $\alpha$-microglobulin-1; $\mathrm{p}<0.05$ indicates significant difference versus the null hypothesis that AUC $=$ 0.5 .

\section{Discussion}

Duration till delivery of studied women who presented by manifestations of TPTL was positively correlated with cervical length (CL), while was negatively correlated with positive FFN and PAMG-1 tests of cervical secretion sample. Positive FFN test had high specificity and +LR, while positive PAMG-1 test had high sensitivity for detecting women who will get labor within 7 days after sampling among studied women presented by manifestations of TPTL. However, 
negative PAMG-1 test can exclude the possibility of getting labor within 7 days with high NPV. These findings indicate the possibility of reliance on these rapid tests for prediction of outcome of women presented by TPTL and so can help management decision-making regarding hospital admission with its related costs and consumption of hospital resources.

Moreover, Regression analysis defined short CL and positive PAMG-1 test as significant predictors for short duration between sampling time and getting labor. Differentially, ROC curve analysis defined short cervix as significant predictor for labor within 48-hr, while positive PAMG-1 test was a significant specific predictor for postponing labor within a range of $2-7$ days and combined negative PAMG-1 test and CL in range of $20-25 \mathrm{~mm}$ were significant predictors for delivery between 7 and 14 days, while positive FFN test was non-significant predictor for delivery within the range of 7 - 14 days.

These data go in hand with Nikolova et al. [22] who reported that in patients presenting with symptoms of PTL with intact membranes and minimal cervical dilatation $(\leq 3 \mathrm{~cm})$ positive PAMG-1 test indicated spontaneous PTB within 7 days with a high degree of accuracy, but negative result indicated unlikelihood of spontaneous PTL within 14 days and in a comparative study versus FFN and CL, Nikolova et al. [23] found PAMG-1 detection is the best predictor of imminent spontaneous delivery within 7 days with sensitivity, specificity, PPV and NPV of $80 \%, 95 \%, 76 \%$ and $96 \%$, respectively. Also, Werlen et al. [24] confirmed the excellent specificity and PPV of PAMG-1 test and documented that dependence on PAMG-1 test of can allow reduction of the rate of unnecessary hospitalization. Thereafter, Ehsanipoor et al. [25] reported that the presence of PAMG-1 in cervical secretion of women presented by TPTL is associated with an increased likelihood of delivery within 7 days with sensitivity and specificity rates of $54.6 \%$ and $82.7 \%$, and PPV and NPV of $31.6 \%$ and $92.5 \%$, respectively. Moreover, Zork et al. [26] found the PPV of FFN for delivery within 7 and 14 days in both singletons and twins with a $\mathrm{CL}<10$ or $11-25 \mathrm{~mm}$ was low (10\%-25\%).

In line with the obtained results concerning the diagnostic performance of PAMG-1 test, Di Fabrizio et al. [27] reported that PAMG-1 test had high efficacy to identify women at risk of imminent PTL within 7 days of testing, and its high NPV can prevent unnecessary admission and therapies and Melchor et al. [28] found the PPV of PAMG-1 was significantly higher than FFN or phosphorylated insulin-like growth factor-binding protein-1 in predicting spontaneous PTB within 7 days of testing in women with TPTL. Recently, Lotfi et al. [29] found PAMG-1 test was statistically superior to standard clinical assessment alone, with respect to specificity in risk assessment of imminent spontaneous PTL in patients with symptoms of TPTL and negative PAMG-1 test result can reduce up to $91 \%$ of unnecessary admissions for women presenting with TPTL.

The obtained results concerning the diagnostic performance of PAMG-1 test and review of literature spot light on its efficacy to be used as the sole rapid bed-side test for predicting outcome of women had manifestations of TPTL. In 
support of the efficacy of PAMG-1 test, Ravi et al. [30] compared the qualitative FFN test at $50 \mathrm{ng} / \mathrm{ml}$ threshold to PAMG-1 test for assessing risk of imminent spontaneous PTB in women with symptoms of PTL and found PAMG-1 test is a better predictor of spontaneous delivery within $7 \mathrm{~d}$ while maintaining a very high NPV. Also, Melchor et al. [31] found positive PAMG-1 test was $>4$ times more reliable than positive FFN test in predicting imminent spontaneous PTL and is a more reliable biomarker which is associated with fewer false-positive results that could lead to a reduction in unnecessary admissions, interventions and use of hospital resources.

\section{Conclusion}

The PAMG-1 test had high specificity, if positive, for predicting and high NPP, if negative, for excluding labor within 7 days in women with TPTB manifestations, so it can be used as a rapid adjuvant to clinical evaluation to help management decision-making. Moreover, the use of PAMG-1 test is recommended for its advantages for being an easy-to-use bedside test, provides rapid results, can be used after vaginal exam and coitus and does not require a speculum examination or specialized equipment to analyze results.

\section{Limitations}

One of the limitations of the current study was the small sample size, but this was due to the low incidence of TPTB and conduction of the study in a single institute. Another limitation was the absence of control group to estimate the levels of these parameters in women with normally progressing women.

\section{Recommendation}

Wider scale multicenter comparative studies are mandatory to establish the obtained results and suggestions.

\section{Conflicts of Interest}

The authors declare no conflicts of interest regarding the publication of this paper.

\section{References}

[1] Songthamwat, S., Na Nan, C. and Songthamwat, M. (2018) Effectiveness of Nifedipine in Threatened Preterm Labor: A Randomized Trial. International Journal of Women's Health, 10, 317-323. https://doi.org/10.2147/IJWH.S159062

[2] Desplanches, T., Lejeune, C., Cottenet, Sagot, P. and Quantin, C. (2018) Cost-Effectiveness of Diagnostic Tests for Threatened Preterm Labor in Singleton Pregnancy in France. Cost Effectiveness and Resource Allocation, 16, 21. https://doi.org/10.1186/s12962-018-0106-y

[3] Chiossi, G., Saade, G.R., Sibai, B. and Berghella, V. (2018) Using Cervical Length Measurement for Lower Spontaneous Preterm Birth Rates among Women with Threatened Preterm Labor. Obstetrics \& Gynecology, 132, 102-106. 
https://doi.org/10.1097/AOG.0000000000002695

[4] Hiersch, L., Yogev, Y., Domniz, N., Meizner, I., Bardin, R. and Melamed, N. (2014) The Role of Cervical Length in Women with Threatened Preterm Labor: Is It a Valid Predictor at Any Gestational Age? American Journal of Obstetrics \& Gynecology, 211, 532.e1-9. https://doi.org/10.1016/j.ajog.2014.06.002

[5] Hermans, F.J.R., Bruijn, M.M.C., Vis, J.Y., Wilms, F.F., Oudijk, M.A., Porath, M.M., Scheepers, H.C.J., Bloemenkamp, K.W.M., Bax, C.J., Cornette, J.M.J., Nij Bijvanck, B.W.A., Franssen, M.T.M., Vandenbussche, F.P.H.A., Kok, M., Grobman, W.A., Van Der Post, J.A.M., Bossuyt, P.M.M., Opmeer, B.C., Mol, B.W.J., Schuit, E. and Van Baaren, G.J. (2015) Risk Stratification with Cervical Length and Fetal Fibronectin in Women with Threatened Preterm Labor before 34 Weeks and Not Delivering within 7 Days. Acta Obstetricia et Gynecologica Scandinavica, 94, 715-721. https://doi.org/10.1111/aogs.12643

[6] Berghella, V. and Saccone, G. (2016) Fetal Fibronectin Testing for Prevention of Preterm Birth in Singleton Pregnancies with Threatened Preterm Labor: A Systematic Review and Metaanalysis of Randomized Controlled Trials. American Journal of Obstetrics \& Gynecology, 215, 431-438. https://doi.org/10.1016/j.ajog.2016.04.038

[7] Faron, G., Balepa, L., Parra, J., Fils, J.F. and Gucciardo, L. (2018) The Fetal Fibronectin Test: 25 Years after Its Development, What Is the Evidence Regarding Its Clinical Utility? A Systematic Review and Meta-Analysis. The Journal of Maternal-Fetal \& Neonatal Medicine, 33, 493-523. https://doi.org/10.1080/14767058.2018.1491031

[8] Honest, H. (2002) Accuracy of Cervicovaginal Fetal Fibronectin Test in Predicting Risk of Spontaneous Preterm Birth: Systematic Review. BMJ, 325, 301. https://doi.org/10.1136/bmj.325.7359.301

[9] Healey, G.K., Macdonald, W.A., Grzybowski, S., Nevin, R., Kornelsen, J. and Hogg, W.E. (2018) Exploring Fetal Fibronectin Testing as a Predictor of Labour Onset: In Parturient Women from Isolated Communities. Canadian Family Physician, 64, e108-e114.

[10] Bruijn, M., Vis, J., Wilms, F., et al. (2016) Quantitative Fetal Fibronectin Testing in Combination with Cervical Length Measurement in the Prediction of Spontaneous Preterm Delivery in Symptomatic Women. BJOG: An International Journal of $O b$ stetrics \& Gynaecology, 123, 1965-1971. https://doi.org/10.1111/1471-0528.13752

[11] Esplin, M.S., Elovitz, M.A., Iams, J.D., Parker, C.B., Wapner, R.J., Grobman, W.A., Simhan, H.N., Wing, D.A., Haas, D.M., Silver, R.M., Hoffman, M.K., Peaceman, A.M., Caritis, S.N., Parry, S., Wadhwa, P., Foroud, T., Mercer, B.M., Hunter, S.M., Saade, G.R. and Reddy, U.M. (2017) nuMoM2b Network: Predictive Accuracy of Serial Transvaginal Cervical Lengths and Quantitative Vaginal Fetal Fibronectin Levels for Spontaneous Preterm Birth among Nulliparous Women. JAMA, 317, 1047-1056. https://doi.org/10.1001/jama.2017.1373

[12] Hezelgrave, N.L., Kuhrt, K., Cottam, K., Seed, P.T., Tribe, R.M. and Shennan, A.H. (2017) The Effect of Blood Staining on Cervicovaginal Quantitative Fetal Fibronectin Concentration and Prediction of Spontaneous Preterm Birth. European Journal of Obstetrics \& Gynecology and Reproductive Biology, 208, 103-108. https://doi.org/10.1016/j.ejogrb.2016.11.027

[13] Petrunin, D.D., Griaznova, I.M., Petrunina, I.A. and Tatarinov, I.S. (1977) Immunochemical Identification of Organ Specific Human Placental Alphal-Globulin and Its Concentration in Amniotic Fluid. Akusherstvo i Ginekologiia, No. 1, 62-64.

[14] Boltovskaia, M.N., Zaraĭskiǔ, E.I., Fuks, B.B., Sukhikh, G.T., Kalafati, T.I., Staros- 
vetskaia, N.A., Nazimova, S.V., Marshitskaia, M.I. and Likharev, V.A. (1991) Histochemical and Clinical-Diagnostic Study of Placental Alpha 1-Microglobulin Using Monoclonal Antibodies. Bulletin of Experimental Biology and Medicine, 112, 397-400. https://doi.org/10.1007/BF00841371

[15] Cousins, L.M., Smok, D.P., Lovett, S.M. and Poeltler, D.M. (2005) AmniSure Placental Alpha Microglobulin-1 Rapid Immunoassay versus Standard Diagnostic Methods for Detection of Rupture of Membranes. American Journal of Perinatology, 22, 317-320. https://doi.org/10.1055/s-2005-870896

[16] Boltovskaia, M.N., Kalinina, I.I. and Popov, G.D. (2002) Expression of Endometrial Proteins in the Uterine Glands in Physiological and Non-Developing Pregnancy. Arkhiv Patologii, 64, 25-28.

[17] Chawanpaiboon, S., Pimol, K. and Sirisomboon, R. (2011) Comparison of Success Rate of Nifedipine, Progesterone, and Bed Rest for Inhibiting Uterine Contraction in Threatened Preterm Labor. Journal of Obstetrics and Gynaecology Research, 37, 787-791. https://doi.org/10.1111/j.1447-0756.2010.01434.x

[18] Berghella, V., Talucci, M. and Desai, A. (2003) Does Transvaginal Sonographic Measurement of Cervical Length before 14 Weeks Predict Preterm Delivery in High-Risk Pregnancies? Ultrasound in Obstetrics \& Gynecology, 21, 140-144. https://doi.org/10.1002/uog.28

[19] Conde-Agudelo, A., Romero, R. and Kusanovic, J.P. (2010) Nifedipine in the Management of Preterm Labor: A Systematic Review and Metaanalysis. American Journal of Obstetrics \& Gynecology, 204, 134.e1-20.

https://doi.org/10.1016/j.ajog.2010.11.038

[20] Ulubaşoğlu, H., Özmen Bayar, Ü., Kaya, C. and Ungan, B. (2015) The Effect of Nifedipine Tocolysis on Doppler Indices of the Uterine and Umbilical Arteries. Journal of Clinical Ultrasound, 43, 322-326. https://doi.org/10.1002/jcu.22252

[21] McNamara, H.C., Crowther, C.A. and Brown, J. (2015) Different Treatment Regimens of Magnesium Sulphate for Tocolysis in Women in Preterm Labour. Cochrane Database of Systematic Reviews, No. 12, CD011200. https://doi.org/10.1002/14651858.CD011200.pub2

[22] Nikolova, T., Bayev, O., Nikolova, N. and Di Renzo, G.C. (2014) Evaluation of a Novel Placental Alpha Microglobulin-1 (PAMG-1) Test to Predict Spontaneous Preterm Delivery. Journal of Perinatal Medicine, 42, 473-477. https://doi.org/10.1515/jpm-2013-0234

[23] Nikolova, T., Bayev, O., Nikolova, N. and Di Renzo, G.C. (2015) Comparison of a Novel Test for Placental Alpha Microglobulin-1 with Fetal Fibronectin and Cervical Length Measurement for the Prediction of Imminent Spontaneous Preterm Delivery in Patients with Threatened Preterm Labor. Journal of Perinatal Medicine, 43, 395-402. https://doi.org/10.1515/jpm-2014-0300

[24] Werlen, S., Raia, T., Di Bartolomeo, A. and Chauleur, C. (2015) Preterm Labor: Reproducibility of Detection Test of PAMG-1 before and after Digital Examination, and Transvaginal Ultrasound Cervical Length. Gynécologie Obstétrique \& Fertilité, 43, 640-645. https://doi.org/10.1016/j.gyobfe.2015.07.002

[25] Ehsanipoor, R.M., Swank, M.L., Jwa, S.C., Wing, D.A., Tarabulsi, G. and Blakemore, K.J. (2016) Placental $\alpha$-Microglobulin-1 in Vaginal Secretions of Women with Evidence of Preterm Labor. American Journal of Perinatology, 33, 208-213. https://doi.org/10.1055/s-0035-1563710

[26] Zork, N., Gulersen, M., Mardy, A., Pessel, C., Brubaker, S., Vink, J., Gyamfi-Bannerman, C. and Ananth, C.V. (2018) The Utility of Fetal Fibronectin in 
Asymptomatic Singleton and Twin Pregnancies with a Cervical Length $<10 \mathrm{~mm}$. The Journal of Maternal-Fetal \& Neonatal Medicine, 1-191. https://doi.org/10.1080/14767058.2018.1562541

[27] Di Fabrizio, L., Giardina, I., Cetin, I., Di Tommaso, M., Ciavattini, A., Locci, M., Facchinetti, F., Zonca, M. and Di Renzo, G.C. (2018) New Methods for Preterm Birth Prediction: The PAMG-1 Test. Minerva Ginecologica, 70, 635-640. https://doi.org/10.23736/S0026-4784.18.04243-0

[28] Melchor, J.C., Khalil, A., Wing, D., Schleussner, E. and Surbek, D. (2018) Prediction of Preterm Delivery in Symptomatic Women Using PAMG-1, Fetal Fibronectin and phIGFBP-1 Tests: Systematic Review and Meta-Analysis. Ultrasound in Obstetrics \& Gynecology, 52, 442-451. https://doi.org/10.1002/uog.19119

[29] Lotfi, G., Faraz, S., Nasir, R., Somini, S., Abdeldayem, R.M., Koratkar, R., Alsawalhi, N. and Ammar, A. (2019) Comparison of the Effectiveness of a PAMG-1 Test and Standard Clinical Assessment in the Prediction of Preterm Birth and Reduction of Unnecessary Hospital Admissions. The Journal of Maternal-Fetal \& Neonatal Medicine, 32, 793-797. https://doi.org/10.1080/14767058.2017.1391782

[30] Ravi, M., Beljorie, M. and El Masry, K. (2018) Evaluation of the Quantitative Fetal Fibronectin Test and PAMG-1 Test for the Prediction of Spontaneous Preterm Birth in Patients with Signs and Symptoms Suggestive of Preterm Labor. The Journal of Maternal-Fetal \& Neonatal Medicine, 32, 3909-3914. https://doi.org/10.1080/14767058.2018.1476485

[31] Melchor, J.C., Navas, H., Marcos, M., Iza, A., De Diego, M., Rando, D., Melchor, I. and Burgos, J. (2018) Predictive Performance of PAMG-1 vs fFN Test for Risk of Spontaneous Preterm Birth in Symptomatic Women Attending an Emergency Obstetric Unit: Retrospective Cohort Study. Ultrasound in Obstetrics \& Gynecology, 51, 644-649. https://doi.org/10.1002/uog.18892 